\title{
Autoinmunidad y autoinflamación
}

\author{
Autoimmunity and autoinflammation
}

\author{
Carlos Alberto Cañas • Cali (Colombia)
}

\section{Resumen}

Objetivo: exponer los aspectos que tienen en común o aquellos que diferencien las condiciones autoinmunes y autoinflamatorias, con énfasis en los mecanismos relacionados con la inmunidad innata.

Métodos: se realiza una revisión sistemática de la literatura médica expuesta en la base de datos Medline (en lo que respecta a trabajos originales y revisiones de tema de los autores de dichos trabajos), de aspectos de la inmunidad innata y su relación con las enfermedades autoinmunes y autoinflamatorias, utilizando términos "MESH" como "autoimmuny diseases, autoinflammatory diseases, periodic fever syndromes, Toll-like receptor, NOD-like receptor" y otros que fuesen necesarios para lograr el objetivo de la revisión. Se procede luego a la consecución de los artículos completos, a su lectura, complementación con artículos referenciados relevantes, y luego se procede al ordenamiento, clasificación y posterior redacción del texto.

Resultados: se estudiaron 254 resúmenes, encontrando que 44 de ellos informaban los tópicos que ayudarán a desarrollar el objetivo de esta revisión. Fue necesario acudir a algunas ayudas extras en libros de inmunología, reumatología, biología molecular y biología celular, para complementar la actualización.

Conclusión: apenas se inicia el conocimiento científico de los posibles enlaces directos de la respuesta inmune innata y adaptativa, en lo que respecta a las condiciones autoinmune y autoinflamatoria (Acta Med Colomb 2011; 36: 78-84).

Palabras clave: enfermedades autoinmunes, enfermedades autoinflamatorias, síndromes febriles periódicos, receptores tipo Toll, receptores tipo NOD.

\footnotetext{
Abstract

Objetive: to show the common aspects and the differences of autoimmune and autoinflammatory conditions, with an emphasis on the mechanisms of innate immunity.

Methods: a systematic review of the literature was performed, using the Medline database, in order to identify original research studies and reviews by the authors of these studies on the topic of innate immunity and its relations with autoimmune and autoinflammatory diseases. "MESH" terms such as autoimmune diseases, autoinflammatory diseases, periodic fever syndromes, Toll-like receptor, NOD-like receptor, and others were necessary to achieve the objective of the review. Sorting, reading, and writing were then carried out.

Results: 254 abstracts were studied, 44 of which reported the topics related to the objective of this review. It was necessary to perform a complementary review of textbooks of immunology, rheumatology, molecular biology, and cell biology to achieve the objective of this review.

Conclusion: scientific knowledge of the possible links between the innate and adaptive immune responses has just begun with regard to autoimmune and autoinflammatory conditions (Acta Med Colomb 2011; 36: 78-84).

Keywords: autoimmune diseases, autoinflammatory diseases, periodic fever syndromes, Toll-like receptor, NOD-like receptor.
}

Dr. Carlos Alberto Cañas Dávila: Internista Reumatólogo, Fundación Valle del Lili, Coordinador Posgrado de Medicina Interna Universidad CES-FVL. Cali (Colombia). Correspondencia. Dr. Carlos Alberto Cañas Dávila, Fundación Valle del Lili, Cali, Colombia.

E-mail: cacd12@hotmail.com

Recibido: 01/XII/2010 Aprobado: 24/V/2011

\section{Introducción}

Los conceptos actuales sobre "autoinmunidad", entendida ésta como la consecuencia de una activación del sistema inmune dirigido contra lo propio, es entendida desde hace más de 100 años. La descripción de la presencia de autoantígenos, autoanticuerpos y células $\mathrm{T}$ autorreactivas, complementan este concepto, el cual lleva a la connotación de una respuesta inmune de tipo adquirida (1). Desde hace una década, se 
empieza a reconocer un nuevo concepto de reactividad del sistema inmune sin la presencia de un autoantígeno, autoanticuerpo o células $\mathrm{T}$ autorreactivas demostrables. Se le ha llamado "autoinflamación", y en la actualidad está implicada en la génesis de varias enfermedades pediátricas que se agrupan en los denominados "síndromes febriles periódicos hereditarios" (2). Sin embargo, basados en la ampliación del conocimiento científico de su patogénesis, se empiezan a discutir si otras enfermedades, incluso de adultos, como la enfermedad de Crohn (3), la enfermedad de Behçet (4), formas de sarcoidosis (5), artropatías por cristales (6), etc., deben incluirse en este grupo de síndromes. La expresión clínica de los procesos autoinmunes sistémicos, y los llamados síndromes autoinflamatorios son similares, y en muchas ocasiones también lo son sus estrategias terapéuticas (7). Desde el punto de vista genético, en las enfermedades autoinmunes se implican múltiples genes en su patogenia, es decir son enfermedades poligénicas (8), a diferencia de las enfermedades autoinflamatorias las cuales tienen un solo gen implicado, es decir, son monogénicas (9). La búsqueda de enlaces entre las condiciones autoinflamatorias y autoinmunes empieza a ser de interés para entender mejor la expresión de muchas enfermedades que tiene componentes de ambas formas de autorreactividad. Así, el objetivo primario de la presente revisión es exponer los aspectos comunes o que diferencien las condiciones autoinmunes y autonflamatorias, con énfasis en los mecanismos relacionados con la inmunidad innata.

\section{Material y métodos}

Se realizó una búsqueda en la base de datos Medline, en lo que respecta a investigaciones publicadas sobre mecanismos relacionados con inmunidad innata y su relación con las enfermedades autoinmunes y autoinflamatorias, utilizando términos "MESH" como "autoimmuny diseases, autoinflammatory diseases, periodic fever syndromes, Toll-like receptor, NOD-like receptor" y otros que fuesen necesarios para llegar al objetivo primario de la revisión, el cual es buscar los puntos de divergencia o convergencia de las condiciones autoinmunes y autoinflamatorias. Se estudiaron alrededor de 250 resúmenes, encontrando que 44 de ellos informaban los tópicos que se necesitaban para realizar la revisión. Se procedió con la consecución de los artículos originales, su lectura, complementación con artículos relevantes que habían sido referenciados, y luego se procedió al ordenamiento, clasificación y posterior redacción del texto. Fue necesario acudir a algunas ayudas extras en libros de inmunología, reumatología, biología molecular y biología celular, para complementar la actualización.

\section{Inmunidad innata y adquirida}

Todos los mecanismos originales o con los que nace un ser vivo como el humano para defenderse de intrusos como los gérmenes, constituyen la llamada inmunidad innata, e incluyen barreras físicas como la piel, células asesinas naturales (natural killer cells-NKC), formas de linfocitos T que activan procesos de destrucción independiente de ser objeto de presentación antigénica como lo requieren otros tipos de linfocitos para su activación (10), y macrófagos, encargados del reconocimiento y fagocitosis de dichos extraños. Hasta aquí el organismo no ha aplicado recursos de memoria contra antígenos previamente reconocidos.

La llamada inmunidad adquirida o adaptativa, por el contrario, defiende al organismo a través de mecanismos aprendidos y más depurados evolutivamente, utilizando dos tipos de células especializadas: 1) linfocitos T de memoria, los cuales orquestan respuestas a elementos muy específicos, basados en la liberación de citoquinas; a lo que se llama inmunidad mediada por células; y 2) células B o linfocitos $\mathrm{B}$, que a través de la producción de anticuerpos llevan a cabo respuestas contra antígenos específicos, y son responsables de la llamada inmunidad humoral (Figura 1).

Existen varias formas de enlace entre la respuesta inmune innata y la adquirida. Una de ellas se inicia con el contacto de los microorganismos con receptores celulares "innatos", llamados "receptores de reconocimiento de patrones" o "PRR", los cuales lo son para lipopolisacáridos (LPS) o motivos "citocina-fosfato- guanocina" (CpG), u otros componentes principalmente de ácidos nucleicos. Los elementos reconocibles por los PRR, son llamados PAMPS (pathogen-associated molecular patterns). Pero no todos los PRR tienen esta función de llevar a cabo una respuesta celular dirigida a la producción de mediadores y activaciones de células de la inmunidad adquirida. Hay receptores que actúan a nivel circulante o en los tejidos, y que solamente están encargados de hacer la destrucción del microorganismo sin activar otros procesos más complejos. El enlace entre la inmunidad innata y adquirida se realiza a través de PRRs que tienen dominios intracitoplasmáticos que pueden activar formas de señalización intracelular, y llevar a la síntesis de moléculas encargadas de iniciar la orquestación de otros cambios celulares para inducir el inicio

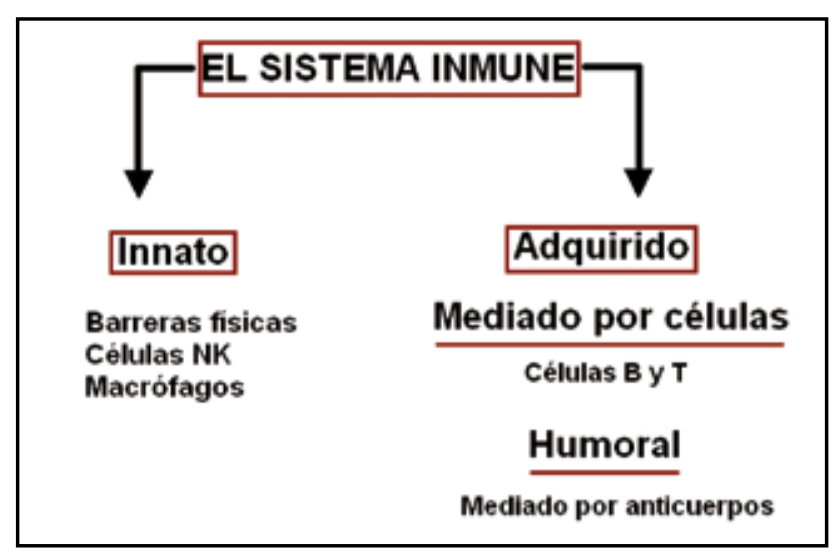

Figura 1. Tipos de respuesta inmune: innata (con la que se nace), como son las barreras físicas, las células asesinas naturales (NK-natural killer), o los macrófagos, entre otros, los cuales nos defienden en forma general, sin dirigirse a antígenos específicos previamente reconocidos; y adquirida o adaptativa, con respuestas a antígenos específicos y previamente reconocidos empleando dos tipos de estrategias, una mediada por células (linfocitos B y $T$ ) y otra con la producción de anticuerpos. 
de los componentes de la inmunidad adquirida. De este tipo de receptores hay unos que son de membrana, como los TLR (Toll-like receptor) (12), y otros intracitoplasmáticos, como los NLR (Nucleotide-binding and oligomerization domainlike receptor) (13). En la Figura 2 se dan a conocer ejemplos de los tres tipos de PRR y su función primaria.

\section{TLR y la autoinmunidad}

Este tipo de receptores altamente conservados durante la evolución, fueron identificados inicialmente en la mosca Drosophila melanogaster (14). Tiene un dominio extracelular rico en leucina interrumpido por motivos de cisteína, y una extensión intracitoplasmática similar al del receptor de la interleuquina-1 (IL-1), con dominios ITAMs que le permite llevar a cabo la cascada de eventos de señalización a través de la fosforilación de residuos de tirosina (15). La cola intracitoplasmática de este tipo de receptores recibe precisamente el nombre de "dominios TIR" que hacen referencia a Toll/IL-1R. Se han identificado 11 tipos de TLR en humanos, algunos permanecen en la membrana celular y son llamados "TLR de membrana" como son los TLR1, TLR2, TLR4 o TLR6, y otros en las membranas endosomales, llamados "TLR endosomales" como son los TLR3,
TLR7, TLR8 y TLR9 (16) (Figura 3). Estos últimos son los más implicados en la generación de respuestas autoinmunes como en el lupus eritematoso sistémico (LES) (17).

Los TLR de membrana una vez activados por la presencia de sus ligandos bacterianos (Ej. LPS en el caso del TLR-4), activan la célula al desencadenar una señalización intracitoplasmática donde se involucran adaptadores como MyD88, Mal(MyD88 adapter-like)/TIRAP(TIR-domain-containing adapter protein), Trif (TIR domain-containing adapter inducing interferon- $\beta$ ) y TRAM (Trif-related adapter molecule). Estos adaptadores son cruciales para el ensamblaje de los complejos de señalización, los cuales incluyen proteinquinasas como IRAK (IL-1 receptor associated kinase) y TRAF (TNF receptor associated factor), responsables también de las respuestas inducidas por las citoquinas de la familia de la IL-1 (IL-1 $\alpha$, IL-1 $\beta$, IL-18 e IL-33) y del factor de necrosis tumoral- $\alpha$ (TNF- $\alpha)$, respectivamente. Esto lleva finalmente a la activación de factores de transcripción como son el NF$\varkappa \mathrm{B}$ o el AP-1, y la síntesis de citoquinas proinflamatorias (18). Los TLR endosomales como el TLR-9, se activan al unirse con residuos $\mathrm{CpGs}$ bacterianos o virales no metilados, llevando también a la respuesta final de la participación del NF- $x$ B y la síntesis de citoquinas, así como la activación

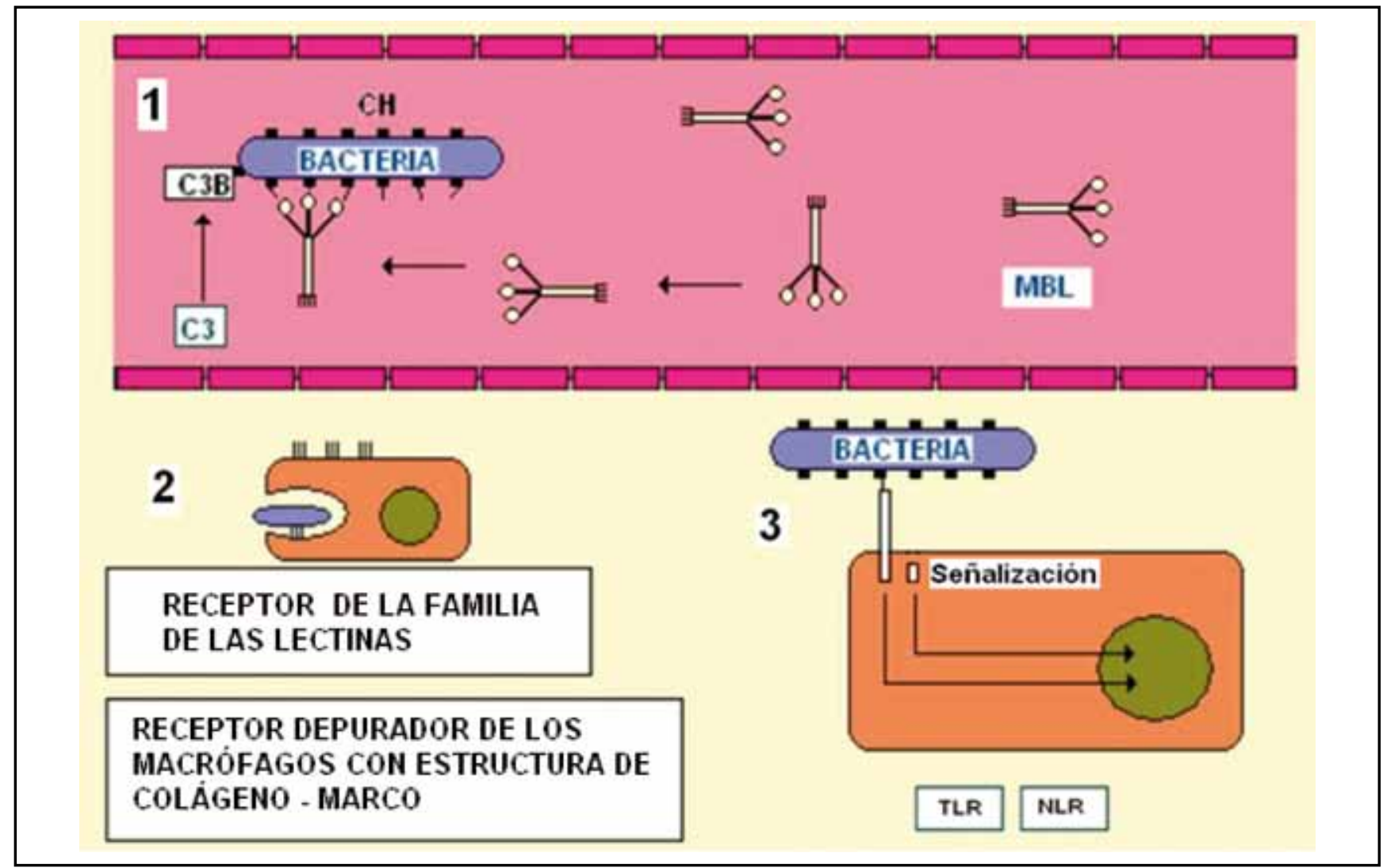

Figura 2. Tipos de PRR ("receptores de patrones de reconocimiento"). 1. A nivel circulante, los receptores solubles en este caso MBL ("lectinas que se unen a manosas"), pueden activar la vía alterna del complemento y así destruir el microorganismo intruso. 2. A nivel tisular, los receptores de la familia de las lectinas unidas a macrófagos, se unen al microorganismo y ejercen una función de fagocitosis, pero no conlleva a una respuesta intracelular especial. 3. También a nivel tisular, los componentes de los gérmenes son reconocidos por dos tipos de receptores, unos a nivel de membrana celular (TLR-"Toll-like receptor") y otros a nivel intracitoplasmático (NLR- "Nod-like receptor") que llevan a señalización intracelular, activación celular y síntesis de proteínas como citoquinas que van a llevar a cabo la activación de componentes de inmunidad adquirida. 


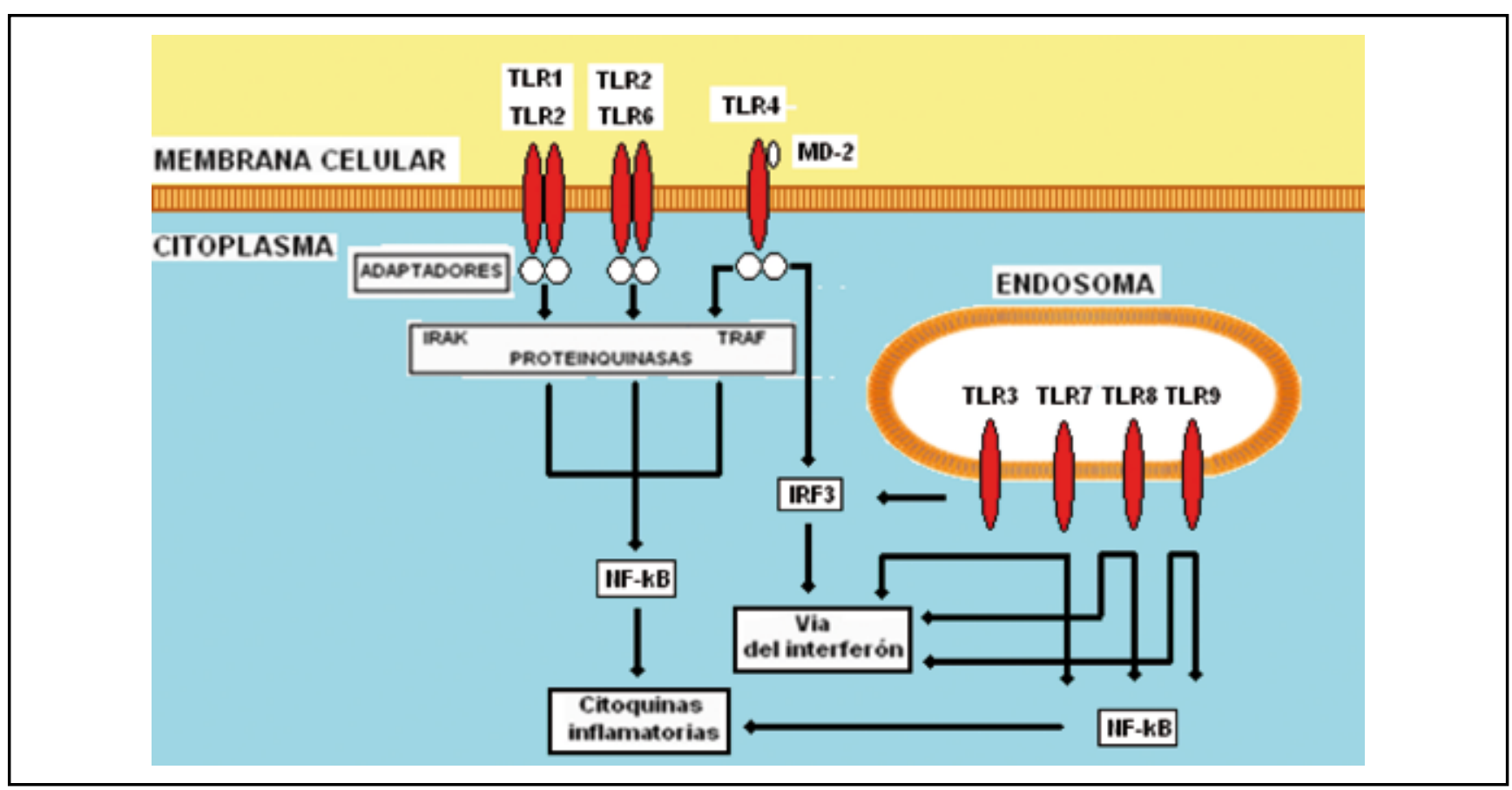

Figura 3. TLR de membrana y endosomales con las vías de señalización en forma esquemática.

de los IFR (interferon response factor) -3 o -7 , los cuales son factores de transcripción que aumentan la expresión de genes de los interferones (INF) tipo 1 (INF- $\alpha$ e INF- $\beta$ ) (19).

La relación de la unión de CpGs bacterianos con el TLR-9 y el desencadenamiento de una respuesta de tipo autoinmune está soportada en estudios in vitro donde se demuestra un aumento de la acción de linfocitos B en cultivos al suministrarles CpGs (20). Esta activación es mucho más fuerte en linfocitos B de pacientes con LES (21). En animales con susceptibilidad para realizar autoinmunidad tipo lupus, se ha demostrado un incremento en la producción de anti-DNA a través de estos mecanismos, así como una activación de componentes de la inmunidad celular $(22,23)$.

Las enfermedades autoinmunes, como se ha comentado antes, son enfermedades poligénicas, y se implican genes tanto de los tipos HLA como "no HLA". Una vez existe esta predisposición genética, intervienen factores medioambientales (Ej., exposición a gérmenes, medicamentos, tóxicos o a la luz ultravioleta), condicionándose una activación celular y de mediadores bioquímicos, que llevan a reacciones inflamatorias tisulares con sus manifestaciones clínicas propias. Se concluiría este concepto con el de "el mosaico de la autoinmunidad", donde se plantea que existen "genes comunes para enfermedades diversas", base de las investigaciones del Dr. Juan-Manuel Anaya (24). La variabilidad en la presentación clínica de las enfermedades autoinmunes como en el LES también se explica en parte a través de la forma de expresión de los TLRs (25). Ratones susceptibles de autoinmunidad inducida con anti-RNP a los cuales se les hace por diferentes mecanismos sobre-expresar TLR-3 y TLR-7, desarrollan enfermedad pulmonar intersticial (26), y el estímulo aislado del TLR-7 les induce enfermedad renal (27). Ratones modelo de lupus además knock-out para el TLR-7, desarrollan enfermedad renal leve, otros knock-out para TLR-9 presentan enfermedad renal severa y manifestaciones cutáneas (28).

En cuanto el TLR-3, diferentes estudios han demostrado una relación entre su expresión tisular y su relación con efectos patológicos locales; así, su expresión se ve incrementada en células glomerulares en condiciones renales autoinmunes $(29,30)$. En artritis reumatoide (AR), se ha encontrado abundante expresión de TLR-3 en células sinoviales (31).

\section{NLR y la autoinflamación}

Los NLR son un grupo de moléculas intracitoplasmáticas que cumplen funciones de receptores y responden a patógenos o a diversas "señales de peligro" que son censados en la membrana y alteran canales de potasio, y motivan la salida de este electrolito. La activación de estos receptores desencadena respuestas inflamatorias (32). Se han descrito 22 proteínas de este grupo, con dominios altamente conservados, ligandos de varias proteínas de la familia de las caspasas, llamadas “caspasas inflamatorias". El grupo de los NLR se dividen en dos familias, una la de los NODs con cinco miembros (del NOD-1 al NOD-5) y otra, la de los NALP (su nombre se deriva de los dominios que lo conforman: NACHT, NTPasa implicated in apoptosis and multihistocompatibility complex transcription; LRR, leucine-rich-repeat; $y$ pyrin domain-containing protein) con 17 miembros, que una vez unidos a diferentes dominios se conocen con el nombre de "inflamasomas" (33). Este último término se acuñó hace una década para describir una molécula intracelular compleja 
que procesa el paso de la pro-IL-1 $\beta$ (35kd) a la activa IL- $1 \beta$ (forma de 17kd).

$\mathrm{El}$ inflamasoma puede tener diferentes formas, sin embargo, el prototipo está compuesto de un componente NALP unido a una molécula de caspasa-1 (Figura 4).

Uno de los inflamasomas más relevante es el NALP3 o "criopirina" (34), esencial para producción de citoquinas de la familia de la IL-1, y su activación inadecuada está implicada en artropatías por cristales como la gota (35). Una mutación en el dominio "NACHT" ocasiona el síndrome llamado FCAS (Familiar cold autoinflammatory síndrome, OMIM 120100), una forma de fiebre periódica hereditaria o enfermedad autoinflamatoria que se manifiesta con urticaria relacionada con el frío, artralgias y conjuntivitis (36). Una mutación en el dominio "pyrin” asociado (más exactamente en su fracción B 30-2), ocasiona la fiebre mediterránea familiar (OMIM 249100), otra enfermedad autoinflamatoria que ocasiona fiebre, peritonitis, eritema erisipeloide y artritis (37). Otras mutaciones del NALP3 están implicadas en el síndrome de Muckle-Wells (MWS, OMIM 191900) y el síndrome CINCA (OMIM 607115, también conocido como NOMID o "neonatal-onset multisystem inflammatory disease). Este último se caracteriza por meningitis crónica estéril, una peculiar osteoartropatía de rodillas y brote similar a urticaria pero no pruriginoso $(38,39)$.

De otra parte una mutación del dominio NACHT del complejo molecular NOD 2, ocasiona el síndrome de Blau (186580), una forma de sarcoidosis juvenil con compromiso osteoarticular, ocular, cutáneo y rara vez pulmonar (40). Otra mutación en el dominio LLR, está implicada en la enfermedad de Crohn (3).

\section{Activación de citoquinas de la familia de la IL-1}

Todos los procesos antes anotados, tanto los iniciados por los TLRs como los NLRs, llevan a la activación de citoquinas de la familia de la IL-1 (IL-1 $\alpha$, IL-1 $\beta$, IL-18 e IL-33) (Figura $5)$. Como ya se mencionó la proIL- $1 \alpha$ o proIL- $1 \beta$ requieren para su activación la caspasa-1, punto de confluencia de las dos vías de activación, iniciando así los procesos propios de la inmunidad adquirida o adaptativa. Las funciones proinflamatorias de estas citoquinas son el resultado de iniciar varios fenómenos a diferentes niveles: activación de moléculas de adhesión, activación de células asesinas naturales, inducción de otras citoquinas proinflamatorias como el TNF- $\alpha$ y la IL6 , producción de anticuerpos, efecto procoagulante, efectos pirogénicos, inducción de colagenasas, entre otros $(41,42)$.

\section{Aspectos clínicos de las enfermedades autoinmunes vs. enfermedades autoinflamatorias}

Tanto las enfermedades autoinmunes sistémicas como las autoinflamatorias, tiene componentes comunes que son el resultado de la liberación de citoquinas proinflamatorias, con manifestaciones de tipo general o constitucional (fiebre,

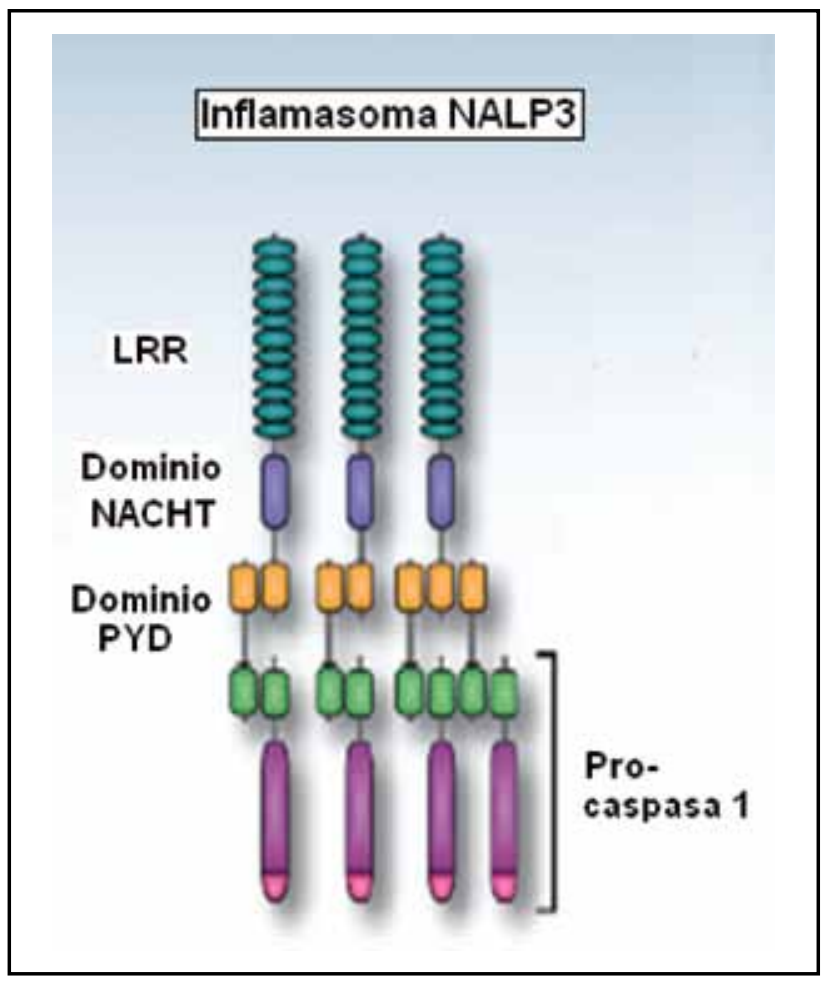

Figura 4. Inflamasoma prototipo, con los dominios LRR (leucine-rich-repeat), NACHT (NTPasa implicated in apoptosis and multihistocompatibility complex transcription), y PYD (pyrin domain). Adaptado de referencia 41.

malestar general, anorexia o pérdida de peso), musculoesqueléticas, cutáneas, oculares, cardiopulmonares, neurológicas, digestivas, renales, hematológicas o vasculares. Dependiendo de cada síndrome, unas manifestaciones son más relevantes que otras.

Las enfermedades autoinflamatorias típicas, constituyen el grupo de los síndromes periódicos hereditarios, de aparición en la infancia y con connotación racial (vg. mediterránea). Sin embargo, es muy interesante que a medida que se vayan conociendo mejor los aspectos patogénicos de varias enfermedades inflamatorias "idiopáticas" de los adultos (Ej. enfermedad de Crohn, gota, artropatía por cristales de pirofosfato, enfermedad de Behçet, enfermedad de Still clásica), se van encontrando similitudes patogénicas con dichos síndromes pediátricos. Una definición de los procesos autoinflamatorios que engloba los conocimientos antes anotados sería: "Procesos caracterizados por ataques recurrentes de inflamación sin evidencia de un autoantígeno, sin desencadenarse la producción de autoanticuerpos o de células T autorreactivas" (43).

Las enfermedades autoinmunes, por el contrario se entran a definir basadas en varias "evidencias": directas, como el hecho de ser mediadas por autoanticuerpos o por células $\mathrm{T}$ autorreactivas; indirectas, basadas en modelos animales con inmunizaciones experimentales, desencadenamiento de sistemas idiotipo-antiidiotipo o por medio de la generación por diversos mecanismos, de disregulación del sistema in- 


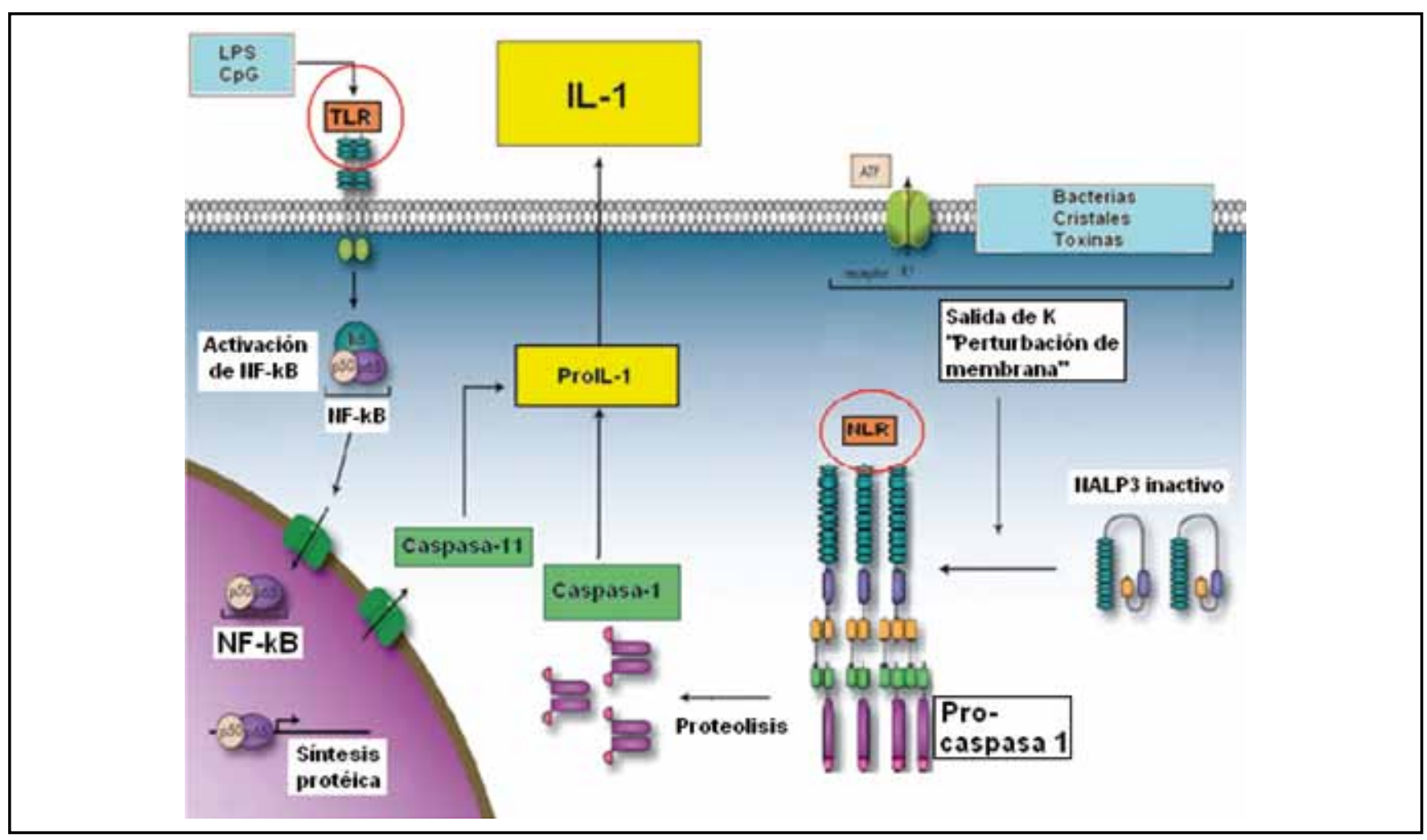

Figura 5. Producción de interleuquina-1 (IL-1) a través de activación de "Toll-like receptor" (TLR) y "NOD-like receptor" (NLR). La proIL-1 $\alpha$ o proIL-1 $\beta$ requieren para su activación la caspasa-1, punto de confluencia de las dos vías de activación, una iniciada por la acción de los receptores de membrana TLR, y otra por los receptores intracitoplasmáticos NLR, así se logra una forma de enlace de la inmunidad innata con la adquirida o adaptativa. Adaptado de referencia 41.

mune; circunstanciales por la presencia de autoanticuerpos, asociación con otras enfermedades autoinmunes, asociación con moléculas del complejo mayor de histocompatibilidad, presencia de infiltración linfocítica en los órganos afectados, o respuesta favorable a la inmunosupresión (44).

\section{Enlaces entre la respuesta innata mediada por receptores TLR y NLR y la inmunidad adquirida}

El enlace entre la respuesta innata mediada por los TLRs y la inmunidad adquirida o adaptativa, como proceso que lleve a generar una forma de inmunidad antígeno específica, ha sido expuesta, y es la base para entender parte de la patogenia de las enfermedades autoinmunes sistémicas tipo LES. Alteraciones en este tipo de respuesta, están también implicadas en la susceptibilidad a ciertas infecciones, patogénesis de varias enfermedades neoplásicas, alérgicas o ateroesclerosis, entre otras (45).

Pero, ¿podría existir un enlace similar entre la respuesta mediada por los NLR y una respuesta adaptativa?, incluso ¿podría existir algún nexo entre las formas de respuesta autoinflamatoria y autoinmune?. Recientemente se empieza a implicar a los NOD1, en la generación de respuesta inmune adaptativa mediada tanto por células $\mathrm{T}$ como por anticuerpos específicos. Estos mecanismos parecen ser cruciales para la respuesta a ciertas infecciones, como lo es para el ántrax (46) o la influenza (47). Además se conoce que la estimulación del NOD1 lleva a una polarización de la respuesta inmune de la Th1 a la Th2 o Th17 (48).

De otra parte, una forma de autoanticuerpos (respuesta autoinmune), han sido recientemente descritos, están dirigidos contra proteínas que tienen funciones regulatorias de TLR, como es la proteína “ARE”, relacionada con RNA de interferencia (RNAi) que hace regulación postranscripcional del RNA mensajero (mRNA) del TRAF e IRAK, proteinquinasas necesarias para la señalización de dichos TLR. Una falta de regulación en la señalización estaría implicada en la sobreexpresión de citoquinas proinflamatorias como el TNF- $\alpha$ y la IL-1. Los anticuerpos contra "iRNA/ARE" están asociados con LES activo (49). Una forma de respuesta de anticuerpos contra componentes regulatorios de repuestas mediadas por NLR aún no ha sido descrita.

\section{Conclusiones}

Existen varias diferencias y similitudes entre la autoinmunidad y la autoinflamación. Ambas condiciones llevan a procesos inflamatorios tisulares, que si son lo suficientemente intensos y perseverantes se genera cicatrización y disfunción orgánica. Los fenómenos autoinmunes son poligénicos mientras los autoinflamatorios son monogénicos. Ambos procesos se pueden desencadenar a través de la unión de receptores celulares con componentes medioam- 
bientales como ciertos patógenos, unos que se encuentran en la membrana celular (TLR) responsables de inicio de respuesta inmune adaptativa en condiciones autoinmunes, y otros intracitoplasmáticos (NLR) responsables directos de generación de una respuesta inflamatoria mediada por citoquinas, desencadenándose una condición autoinflamatoria. Un enlace directo de los NLR con una respuesta inmune adaptativa empieza a dilucidarse.

\section{Referencias}

1. Iglesias-Gamarra A. Historia del lupus. Primera edición. Panamericana, Bogotá. 2003; 103-134

2. Stojanov S, Kastner DL. Familial autoinflammatory diseases: genetics, pathogenesis and treatment. Curr Opin Rheumatol 2005; 17: 586-99.

3. Hugot JP, Chamaillard M, Zouali H, Lesage S, Cézard JP, Belaiche J, et al. Association of NOD2 leucine-rich repeat variants with susceptibility to Crohn's disease. Nature 2001; 411: 599-603.

4. Krause I, Weinberger A. Behçet's disease. Curr Opin Rheumatol 2008; 20: 82-7.

5. Manouvrier-Hanu S, Puech B, Piette F, Boute-Benejean O, Desbonnet A, Duquesnoy B, et al. Blau syndrome of granulomatous arthritis, iritis and skin rash: a new family and review of the literature. Am J Med Genet 1998; 76: 217-21.

6. Martinon F. Mechanisms of uric acid crystal-mediated autoinflammation. Immunol Rev 2010; 233: 218-32.

7. Kiss MHB, Saad C. Autoinflammatory diseases: mimics of autoimmunity or part of its spectrum? Case presentation. Clin Immunol 2008; 28: 84-9.

8. Anaya JM, Gómez LM, Castiblanco J. Is there a Common Genetic Basis for Autoimmune Diseases?. Clin Dev Immunol 2006; 13: 185-95.

9. McDermotta MF,Aksentijevich I. The autoinflammatory syndromes. Curr Opin Allergy Clin Immunol 2002; 2: 511-16.

10. Lanier LL. NK cell recognition. Annu Rev Immunol 2005; 23: 225-74.

11. Akira $S$, Uematsu S, Takeuchi O. Pathogen recognition and innate immunity. Cell 2006; 124: 783-801.

12. Takeda K, Akira S. Toll-like receptors in innate immunity. Int Immunol 2005; 17: $1-14$.

13. Fritz JH, Ferrero RL, Philpott DJ, Girardin SE. Nod-like proteins in immunity, inflammation and disease. Nat Immunol 2006; 7: 1250-7.

14. Lemaitre B, Nicolas E, Michaut L, Reichhart J, Hoffmann J. The dorsoventral regulatory gene cassette spätzle/Toll/cactus controls the potent antifungal response in Drosophila adults. Cell 1996; 86: 973-83.

15. Kawai T, Akira S. TLR signaling. Cell Death Differ 2006; 13: 816-25.

16. Kumar H, Kawai T, Akira S. Toll-like receptors and innate immunity. Biochem Biophys Res Commun 2009; 388: 621-5.

17. Anders HJ. “A toll for lupus”. Lupus 2005; 14: 417-22.

18. Verstrepen L, Bekaert T, Chau TL, Tavernier J, Chariot A, Beyaert R. TLR-4, IL-1R and TNF-R signaling to NF-kappaB: variations on a common theme. Cell Mol Life Sci 2008; 65: 2964-78.

19. Colonna M. TLR pathways and IFN-regulatory factors: to each its own. Eur J Immunol 2007; 37: 306-9.

20. Bernasconi NL, Onai N, Lanzavecchia A. A role for Toll-like receptors in acquired immunity: upregulation of TLR9 by BCR triggering in naive B cells and constitutive expression in memory B cells. Blood 2003; 101: 4500-4.

21. Lafyatis R, Marshak-Rothstein A. Toll-like receptors and innate immune responses in systemic lupus erythematosus. Arthritis Res Ther 2007; 9: 222.

22. Christensen M, Kashgarian L. Alexopoulou RA, Flavell, Akira S, Shlomchik MJ. Toll-like receptor controls anti-DNA autoantibody production in murine lupus. J Exp Med 2005; 202: 321-31.

23. Subramanian S, Tus K, Li QZ, Wang A, Tian XH, Zhou J, et al. A Tlr7 translocation accelerates systemic autoimmunity in murine lupus. Proc Natl Acad Sci U S A 2006; 103: 9970-9975.

24. Shoenfeld Y, Anaya JM. Autoinmunidad y enfermedad autoinmune: el mosaico de la autoinmunidad. En: Anaya JM, Shoenfeld Y, Correa PA, García-Carrasco M, Cervera R, editores. Autoinmunidad y enfermedades autoinmunes. CIB, Medellín 2005: 183-190.

25. Trivedi S, Greidinger EL. Endosomal Toll-like receptors in autoimmunity: mechanisms for clinical diversity. Therapy 2009; 6: 433-42.
26. Greidinger EL, Zang Y, Jaimes K, Hogenmiller S, Nassiri M, Bejarano P,et al. A murine model of mixed connective tissue disease induced with U1 small nuclear RNP autoantigen. Arthritis Rheum 2006; 54: 661-669.

27. Deane JA, Pisitkun P, Barrett RS, Feigenbaum L, Town T, Ward JM, et al. Control of toll-like receptor 7 expression is essential to restrict autoimmunity and dendritic cell proliferation. Immunity 2007; 27: 801-10.

28. Christensen SR, Shupe J, Nickerson K, Kashgarian M, Flavell RA, Shlomchik MJ. Toll-like receptor 7 and TLR9 dictate autoantibody specificity and have opposing inflammatory and regulatory roles in a murine model of lupus. Immunity 2006; 25: 417-428.

29. Patole PS, Pawar RD, Lech M, Zecher D, Schmidt H, Segerer S, et al. Expression and regulation of Toll-like receptors in lupus-like immune complex glomerulonephritis of MRL-Fas(lpr) mice. Nephrol Dial Transplant 2006; 21: 3062-73.

30. Patole PS, Gröne HJ, Segerer S, Ciubar R, Belemezova E, Henger A, et al. Viral double-stranded RNA aggravates lupus nephritis through Toll-like receptor 3 on glomerular mesangial cells and antigen-presenting cells. J Am Soc Nephrol 2005; 16: 1326-38.

31. Brentano F, Schorr O, Gay RE, Gay S, Kyburz D. RNA released from necrotic synovial fluid cells activates rheumatoid arthritis synovial fibroblasts via Toll-like receptor 3. Arthritis Rheum 2005; 52: 2656-65.

32. Kanneganti TD, Ozören N, Body-Malapel M, Amer A, Park JH, Franchi L, et al. Bacterial RNA and small antiviral compounds activate caspase-1 through cryopyrin/Nalp3. Nature 2006; 440: $233-6$.

33. Martinon F, Mayor A, Tschopp J. The inflammasomes: guardians of the body. Annu Rev Immunol 2009, 27: 229-65.

34. Lamkanfi M, Kanneganti TD. NLRP3: an immune sensor of cellular stress and infection. Int J Biochem Cell Biol 2010; 42: 792-5.

35. Dalbeth N, So A. Hyperuricaemia and gout: state of the art and future perspectives. Ann Rheum Dis 2010; 69:1738-43.

36. Gattorno M, Federici S, Pelagatti MA, Caorsi R, Brisca G, Malattia C, et al. Diagnosis and management of autoinflammatory diseases in childhood. J Clin Immunol 2008, 28: 73-83.

37. Bakkaloglu A. Familial mediterranean fever. Pediatr Nephrol 2003; 18: 853-9.

38. Aksentijevich I, D Putnam C, Remmers EF, Mueller JL, Le J, Kolodner RD, et al. The clinical continuum of cryopyrinopathies: novel CIAS1 mutations in North American patients and a new cryopyrin model. Arthritis Rheum 2007; 56: 1273-85.

39. Iglesias-Gamarra A, Rojas A, Calvo E, Restrepo JF. Síndromes que simulan una artritis sistémica juvenil. A propósito de un caso de síndrome de NOMID/ CINCA. Rev Col Reum 2004; 11: 233-42.

40. Alonso D, Elgart G W, Schachner L A. Blau syndrome: a new kindred. J Am Acad Derm 2003; 49: 299-302.

41. Sidiropoulos PI, Goulielmos G, Voloudakis GK, Petraki E, Boumpas DT. Inflammasomes and rheumatic diseases: evolving concepts. Ann Rheum Dis 2008; 67: $1382-9$.

42. Pascual V, Allantaz F, Arce E, Punaro M, Banchereau J. Role of interleukin-1 (IL-1) in the pathogenesis of systemic onset juvenile idiopathic arthritis and clinical response to IL-1 blockade. J Exp Med 2005; 201: 1479-86.

43. McDermott MF, Aksentijevich I. The autoinflammatory syndromes. Curr Opin Allergy Immunol 2002; 2: 511-16.

44. Rose NR, Bona C. Defining criteria for autoimmune diseases (Witebsky's postulates revisited). Immunol Today 1993 Sep; 14: 426-30.

45. Montero Vega MT, de Andrés Martín A. The significance of toll-like receptors in human diseases. Allergol Immunopathol (Madr). 2009; 37: 252-63.

46. Loving CL, Osorio M, Kim YG, Nuñez G, Hughes MA, Merkel TJ. Nod1/ Nod2-Mediated Recognition Plays a Critical Role in Induction of Adaptive Immunity to Anthrax after Aerosol Exposure. Infect Immun 2009; 77: 4529-37.

47. Ichinohe T, Lee HK, Ogura Y, Flavell R, Iwasaki A. Inflammasome recognition of infl uenza virus is essential for adaptive immune responses. J Exp Med 2009; 206: $79-87$.

48. Fritz JH, Le Bourhis L, Sellge G, Magalhaes JG, Fsihi H, Kufer TA, et al. Nod1-mediated innate immune recognition of peptidoglycan contributes to the onset of adaptive immunity. Immunity 2007; 26: 445-59.

49. Jimenez-Boj E, Kedersha N, Tohidast-Akrad M, Karlhofer FM, Stummvol G, Zimmermann $\mathbf{C}$ et al. Autoantibodies to the translational suppressors T cell intracytoplasmic antigen 1 and $\mathrm{T}$ cell intracytoplasmic antigen 1-related protein in patients with rheumatic diseases: increased prevalence in systemic lupus erythematosus and systemic sclerosis and correlation with clinical features. Arthritis Rheum 2008; 58: 1226-36. 